\title{
Radiosensitization effect of Huaier on breast cancer cells
}

\author{
XIA DING ${ }^{1}$, QIFENG YANG ${ }^{2,3}$, XIANGNAN KONG $^{4}$, BRUCE G. HAFFTY ${ }^{5}$, \\ SUMEI GAO ${ }^{2}$ and MEENA S. MORAN ${ }^{6}$
}

\begin{abstract}
Departments of ${ }^{1}$ Oncology and ${ }^{2}$ Breast Surgery, and ${ }^{3}$ Pathology Tissue Bank, Qilu Hospital, Shandong University, Jinan, Shandong 250012; ${ }^{4}$ Laboratory Medicine Center, Qilu Hospital of Shandong University (Qingdao), Qingdao, Shandong 266035, P.R. China; ${ }^{5}$ Department of Radiation Oncology, Rutgers Cancer Institute of New Jersey and Rutgers - Robert Wood Johnson Medical School, New Brunswick, NJ; ${ }^{6}$ Department of Therapeutic Radiology, Yale University School of Medicine, New Haven, CT, USA
\end{abstract}

Received January 14, 2016; Accepted February 4, 2016

DOI: $10.3892 / o r .2016 .4630$

\begin{abstract}
Radiotherapy is a critical treatment strategy for breast cancer. However, its wide application is sometimes restricted by radioresistance and radiotoxicity. Trametes robiniophila Murr. (Huaier), an officinal fungus used as a traditional Chinese medicine (TCM), is reported to have multi-biological functions during cancer treatment. Yet, its radiosensitization effects have not been evaluated to date. In the present study, using HTA 2.0 transcriptome microarray assay, Huaier was found to downregulate genes related to the cell cycle, cell division, cell cycle phases and DNA repair. This investigation utilized a colony formation assay to confirm the ability of Huaier to sensitize breast cancer cells to radiotherapy. Flow cytometry, immunofluorescence staining and western blotting were used to illustrate the sensitization mechanism. Our findings suggest that Huaier causes G0/G1 arrest through downregulation of cell cycle-regulating proteins in MCF-7 and MDA-MB-468 cells, prolongs the persistence of $\gamma$-H2Ax foci after radiotherapy and interferes with the homologous recombination (HR) pathway of DNA repair by downregulating RAD51. These results suggest that Huaier has the ability to sensitize breast cancer cells to radiotherapy through regulation of the cell cycle and DNA repair pathway. Thus, Huaier may be a promising radiosensitizer for the treatment of breast cancer.
\end{abstract}

\section{Introduction}

Breast cancer is one of the most prevalent cancers worldwide and is the main cause of cancer-related mortality among females (1). Conventional treatment strategies mainly include surgery, systemic agents (hormone therapy, chemotherapy and targeted therapy) and radiotherapy. Radiation is a critical

Correspondence to: Professor Qifeng Yang, Department of Breast Surgery, Pathology Tissue Bank, Qilu Hospital, Shandong University, Wenhua Xi Road 107, Jinan, Shandong 250012, P.R. China

E-mail: qifengy_sdu@163.com

Key words: Huaier, breast cancer, radiotherapy, RAD51, DNA repair component of breast cancer treatment modalities and is highly effective in improving locoregional control and allowing for breast conservation without any detrimental effects on survival (2). However, its curative effect is sometimes limited by radioresistance of the cancer cells, in addition to radiation toxicity to normal tissue $(2,3)$. As is well established, the four factors that influence radioresistance are i) repair of DNA, ii) reoxygenation, iii) redistribution of the cell cycle and iv) repopulation (the ' 4 R's'). Thus, any pharmacologic agents aimed at sensitizing cells to radiotherapy would need to target one or more of these factors. While many agents have been explored based on this principle, the side-effects of the agent itself often prohibits its successful use as a radiosensitizer (4-6). Thus, finding novel radiosensitizing agents with minimal side-effects has become an area of interest for radiation oncology investigators. More recently, the interest in plant-derived natural products for breast cancer treatment and symptom management has increased (7-10). Given the multiple antitumor effects of many traditional Chinese medicines (TCMs), exploring these agents as radiosensitization agents is of interest.

Trametes robiniophila Murr. (Huaier) is classified as an officinal fungus which has been used in China as a traditional medicine for many years (11). Previous investigations suggest that Huaier displays multiple antitumor effects against hepatocarcinoma $(12,13)$, gastrointestinal $(14)$, breast $(15,16)$ and lung cancer (17). Several mechanisms for the antitumor activities of Huaier have been suggested including the induction of apoptosis, anti-angiogenesis, reversal of drug-resistance, antimetastasis and activation of the immune system $(15,18-22)$. In addition, in recent years, as a complementary drug, Huaier has been routinely used in liver and breast cancer.

Previously, our research group investigated the mechanisms of action of Huaier and demonstrated the multi-targeted antitumor effects of Huaier (23). We found that a microarray assay of MCF-7 cells treated with Huaier demonstrated that the effects were related to the cell cycle, cell division and DNA repair. Consequently, Huaier may have a radiosensitization effect on breast cancer and the present study was carried out to assess the combined effects of Huaier and radiotherapy on breast cancer. 


\section{Materials and methods}

Cell lines and reagents. The human breast cancer cell lines, MCF-7 and MDA-MB-468, were obtained from the American Type Culture Collection (ATCC; Rockefeller, MD, USA), and were routinely cultured in Dulbecco's modified Eagle's medium (DMEM; Gibco, Rockville, MD, USA) with 10\% fetal bovine serum (FBS; Clark Bioscience, Seabrook, MD, USA), $100 \mathrm{U} / \mathrm{ml}$ penicillin and $100 \mu \mathrm{g} / \mathrm{ml}$ streptomycin in $5 \% \mathrm{CO}_{2}$ at $37^{\circ} \mathrm{C}$. The antibodies utilized included anti-Ku70, -Ku86 and -RAD51 (Santa Cruz Biotechnology Inc., Santa Cruz, CA, USA), mouse anti- $\gamma$-H2AX antibody (Millipore, Billerica, MA, USA), Rhodamine-labeled secondary antibody (Jackson ImmunoResearch, West Grove, PA, USA) and HRP-labeled secondary antibodies (KPL, Gaithersburg, MD, USA). Huaier aqueous extract, a kind gift from Gaitianli Medicine Co. Ltd. (Jiangsu, China), was dissolved in DMEM in a storage concentration of $100 \mathrm{mg} / \mathrm{ml}$. All other chemicals were obtained from Sigma-Aldrich (St. Louis, MO, USA) unless specifically described.

Cell treatment and human transcriptome array 2.0 (HTA 2.0) assay. MCF-7 cells were treated with Huaier aqueous extract at a concentration of $8 \mathrm{mg} / \mathrm{ml}$ for $72 \mathrm{~h}$ or treated with DMEM as a control, and total RNA was isolated according to the manufacturer's protocol using TRIzol (Invitrogen, Carlsbad, CA, USA). Equal amounts of 3 samples of RNAs were pooled together to obtain an average. Gene alterations were detected using Affymetrix Human Transcriptome Array 2.0 (HTA 2.0) assay and fold-change was used to identify differentially expressed genes (DEGs). Next, DEGs were analyzed by Gene Ontology (GO) analysis, which organizes genes into hierarchical categories based on biological processes and molecular function $(24,25)$.

Ionizing radiation treatment. Cells were irradiated using a radiotherapy linear accelerator PRIMUS HI (Siemens, Germany) at room temperature. The X-rays were filtered through a $12-\mathrm{mm}$ thick special organic glass for dose built-up. The irradiation dose rate was $200 \mathrm{cGy} / \mathrm{min}$.

Colony formation assay. The radiosensitization effects of Huaier on breast cancer cells were assessed by colony formation assay. Briefly, the cells were treated with $4 \mathrm{mg} / \mathrm{ml}$ Huaier or complete DMEM as a control for $24 \mathrm{~h}$, and then irradiated with incremental doses of radiation (0-4 Gy) at room temperature. The cells were trypsinized, suspended in complete medium, counted and plated in 6-well plates and incubated for 14-21 days to collect cell colonies. Cell colonies were fixed with methanol and stained with crystal violet. Only colonies containing $>50$ cells were counted. The survival fraction of each given dose (SFD) was calculated using the linear-quadratic formula: $\mathrm{S}(\mathrm{D})=\mathrm{S}(0) \mathrm{e}^{(-\mathrm{-a}-\beta \mathrm{D} 2)}$ and the $\alpha$ and $\beta$ values were obtained to describe survival curve characteristics relative to radiation dose (26).

Cell cycle analysis by flow cytometry. The cell cycle distribution was analyzed using a flow cytometer. Briefly, $5 \times 10^{5}$ cells were seeded in a $25 \mathrm{~cm}^{2}$ flask, and then treated with $4 \mathrm{mg} / \mathrm{ml}$ Huaier or DMEM as control for $24 \mathrm{~h}$ before irradiation. The
Table I. Top 10 GO categories altered in the Huaier-treated MCF-7 cells compared to the control cells.

\begin{tabular}{lcc}
\hline GO name & P-value & FDR \\
\hline Cell division & $9.28252 \mathrm{E}-51$ & $6.45599 \mathrm{E}-48$ \\
DNA replication & $1.92587 \mathrm{E}-50$ & $8.92961 \mathrm{E}-48$ \\
G1/S transition of mitotic & $2.89469 \mathrm{E}-39$ & $1.00663 \mathrm{E}-36$ \\
cell cycle & & \\
Mitotic prometaphase & $7.24882 \mathrm{E}-38$ & $2.01662 \mathrm{E}-35$ \\
M phase of mitotic cell cycle & $4.05311 \mathrm{E}-36$ & $9.39646 \mathrm{E}-34$ \\
S phase of mitotic cell cycle & $1.86134 \mathrm{E}-34$ & $3.69876 \mathrm{E}-32$ \\
DNA repair & $7.23594 \mathrm{E}-32$ & $1.25815 \mathrm{E}-29$ \\
DNA strand elongation involved & $1.06698 \mathrm{E}-30$ & $1.64908 \mathrm{E}-28$ \\
in DNA replication & & \\
Mitosis & $1.17413 \mathrm{E}-27$ & $1.63322 \mathrm{E}-25$ \\
Mitotic anaphase & $2.69998 \mathrm{E}-26$ & $3.41424 \mathrm{E}-24$ \\
\hline
\end{tabular}

FDR, false discovery rate; GO, Gene ontology.

cells were then trypsinized, washed with phosphate-buffered saline (PBS), incubated with $1 \mathrm{ml}$ propidium iodide (PI) (Liankebio, Zhejiang, China) in the dark for $30 \mathrm{~min}$ at room temperature, and then analyzed using a flow cytometer (Becton-Dickinson, Franklin Lakes, NJ, USA). The data were analyzed using ModFit LT V2.0 software (Becton-Dickinson).

Immunofluorescence staining. Conditions of $\gamma-\mathrm{H} 2 \mathrm{AX}$ foci were detected using immunofluorescence staining. The cells were grown on coverslips in 24-well plates and pretreated with $4 \mathrm{mg} / \mathrm{ml}$ Huaier or DMEM (control) for $24 \mathrm{~h}$ before irradiation. The cells were washed in PBS, and then fixed with $4 \%$ paraformaldehyde for $15 \mathrm{~min}$ followed by treatment with $0.2 \%$ Triton X-100 for $8 \mathrm{~min}$. Then, the cells were washed in PBS, blocked with $10 \%$ normal goat serum in PBS for $1 \mathrm{~h}$, and incubated with mouse anti- $\gamma-\mathrm{H} 2 \mathrm{AX}$ antibody overnight at $4^{\circ} \mathrm{C}$. After washing in PBS, the cells were incubated with Rhodamine-conjugated anti-mouse secondary antibody in the dark for $1 \mathrm{~h}$. The cells were then washed in PBS, and stained with 4',6-diamidino-2-phenylindole (DAPI). Then after washing in PBS for 3 times, the coverslips were mounted on glass slides with anti-fading medium (Beyotime Institute of Biotechnology, Jiangsu, China). The fluorescence signal was acquired using a fluorescence microscope (Olympus, Tokyo, Japan).

Western blot analysis. Cells were lysed with radioimmunoprecipitation assay (RIPA) and phenylmethanesulfonyl fluoride (PMSF) (Biocolors, Shanghai, China), and quantified by the BCA method (Merck, Darmstadt, Germany). Equal amounts of protein were loaded on SDS-PAGE gel, and then transferred to PVDF membranes (Millipore, Bedford, MA, USA). After blocking in 5\% defatted milk for $1 \mathrm{~h}$ at room temperature, the membranes were incubated with the corresponding primary antibody overnight at $4^{\circ} \mathrm{C}$. The next day, the membranes were washed in TBST three times prior to incubation with the corresponding secondary antibody for $2 \mathrm{~h}$. Signals were detected using Luminescent Image Analyzer (GE Healthcare Life Sciences, Sweden). $\beta$-actin was used as the loading control. 
A

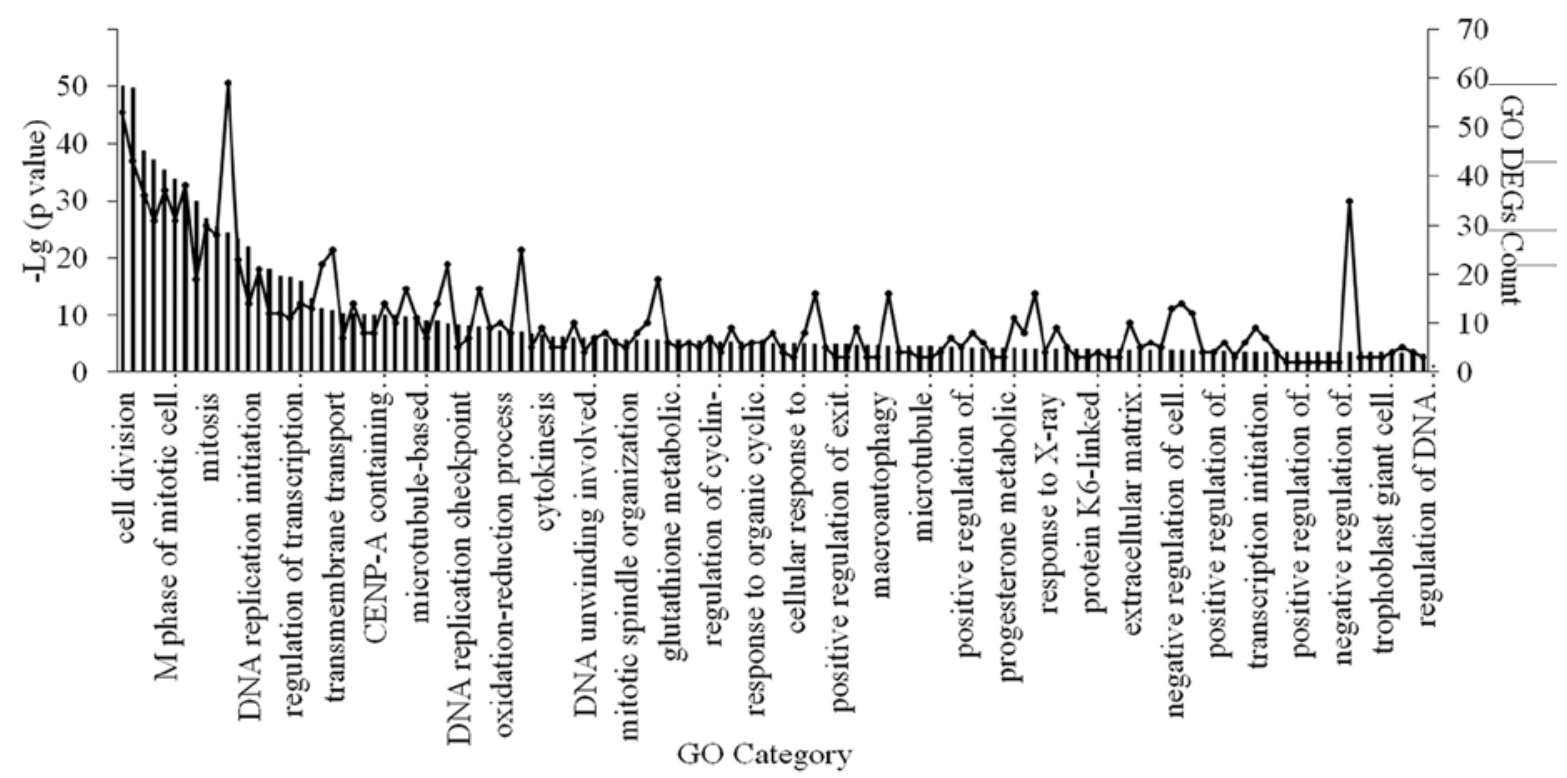

B

MCF-7

MDA-MB-468

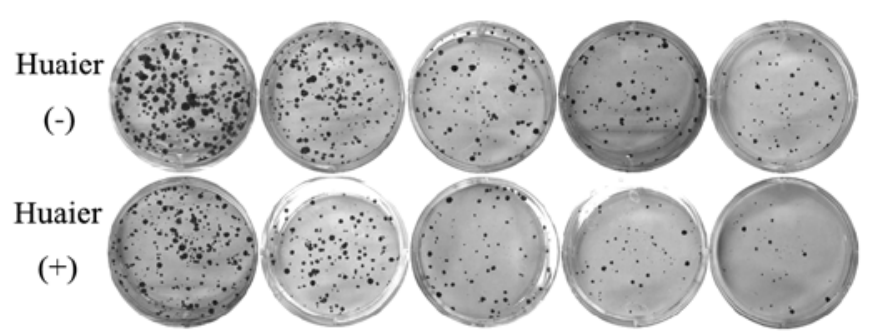

MCF-7

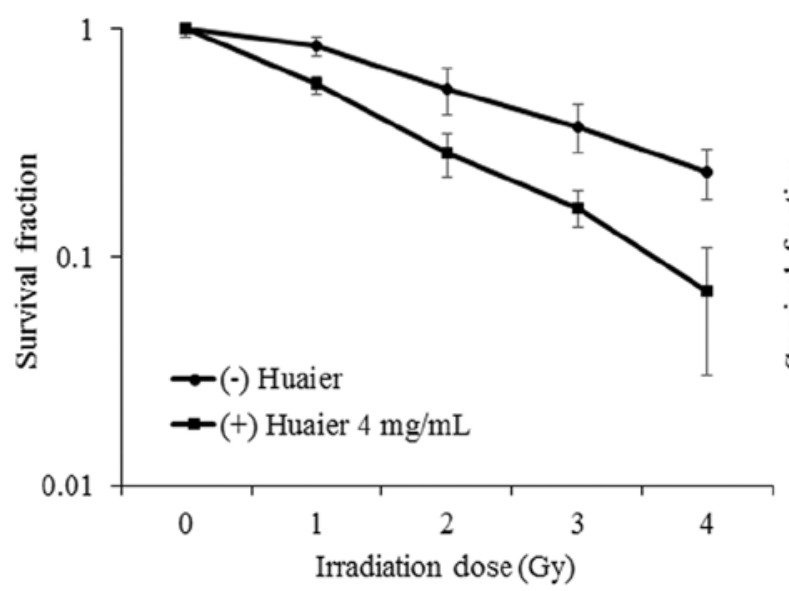

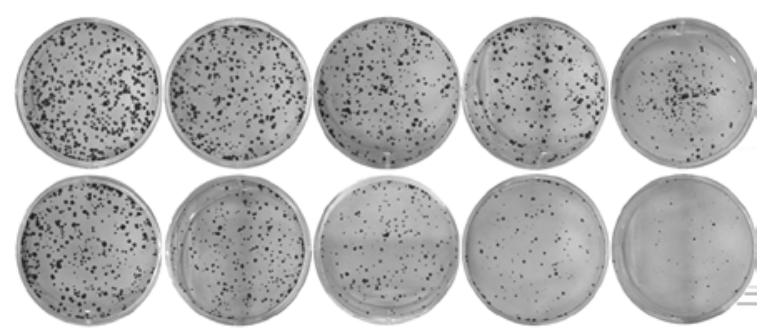

MDA-MB-468

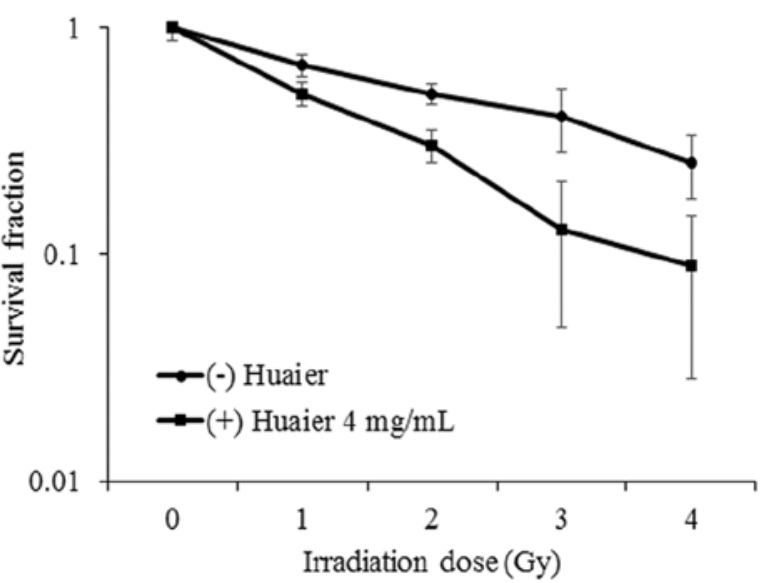

Figure 1. Huaier sensitizes breast cancer cells to irradiation. (A) GO analysis results of the MCF-7 cells after Huaier treatment. Huaier altered biological activities mainly related to cell cycle, cell division, cell cycle phases and DNA repair. The columns indicate the regulated GO categories with -Lg (p-value) listed on the left. The line chart indicates the count of regulated genes that each category contains. (B) The survival curves derived from the clonogenic assay experiments treated with or without Huaier were significantly different $(\mathrm{p}<0.01)$ in both the MCF-7 and MDA-MB-231 cell lines. The experiments were performed in triplicate and data are presented as mean \pm SD of three separate experiments.

Statistical analysis. The data are expressed as the mean \pm standard error of the mean (SEM), and each experiment was conducted for a minimum of 3 times. The SPSS 18.0 software (SPSS, Inc., Chicago, IL, USA) was used for statistical analysis. Student's t-test and linear regression analysis were used to analyze the statistical significance. A p-value $<0.05$ was utilized as the threshold for statistical significance.

\section{Results}

Huaier alters biological activities related to cell cycle, cell division and DNA repair. Microarray profiling was obtained and GO analysis was used to detect the altered biological function of MCF-7 cells after treatment of Huaier at $8 \mathrm{mg} / \mathrm{ml}$ for $72 \mathrm{~h}$. As shown in Fig. 1A, the top altered categories were 
A
(-) Huaier

MCF-7

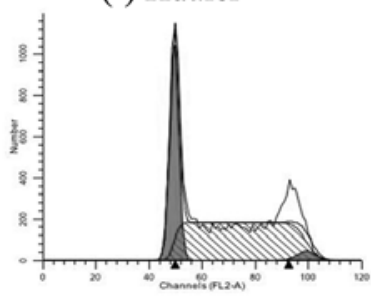

(+) Huaier $4 \mathrm{mg} / \mathrm{mL}$
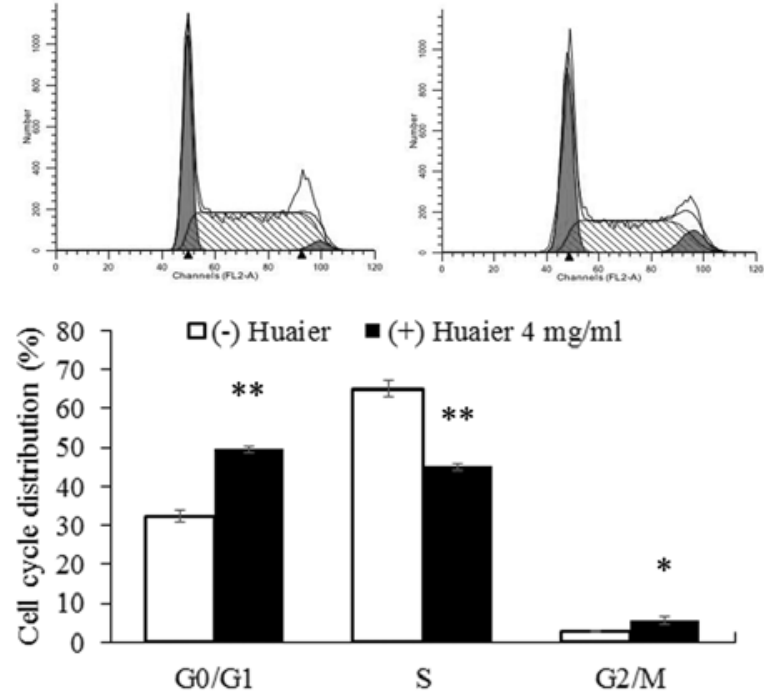

C

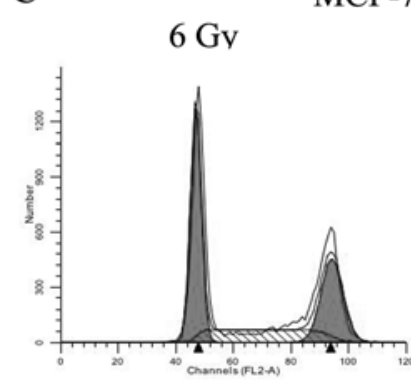

MCF-7 $8 \mathrm{~h}$

$\square(-)$ Huaier

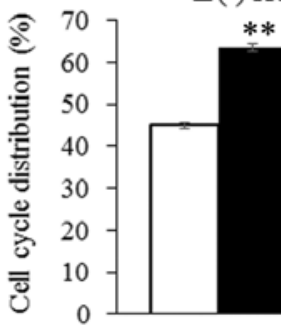

G0/G1

$\mathbf{E}$

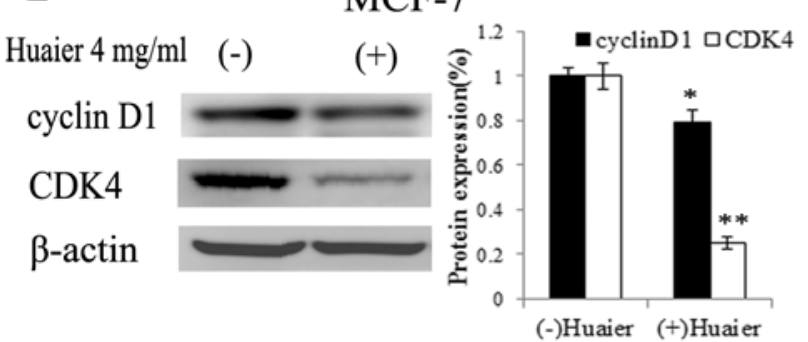

B
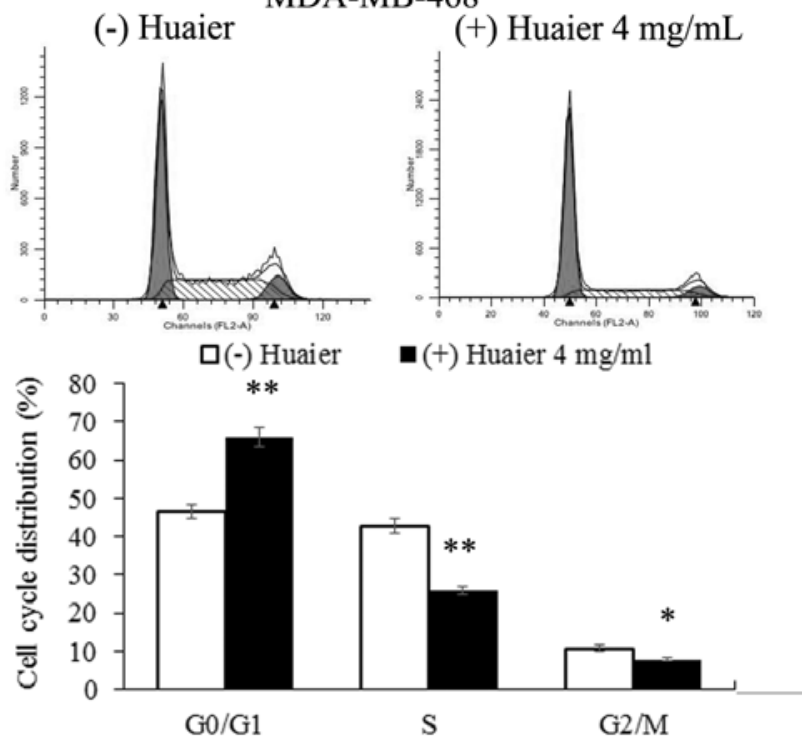

D
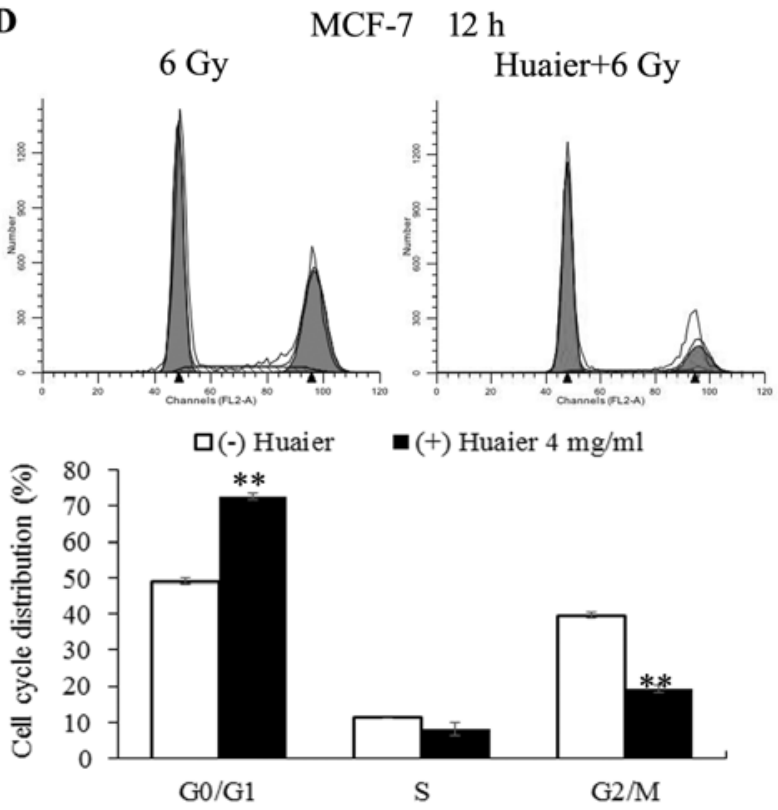

F

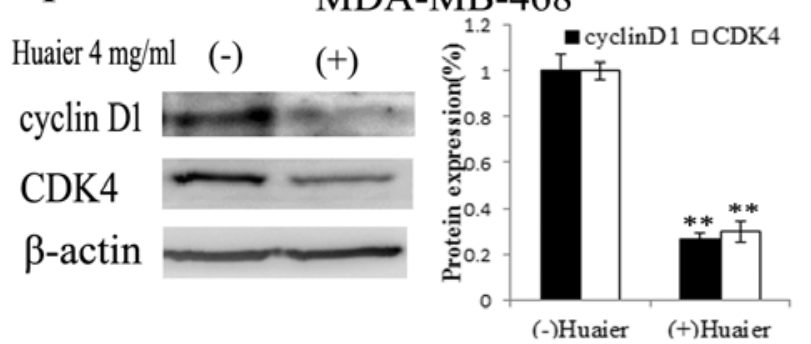

Figure 2. Results of the cell cycle analysis. Huaier induced G0/G1 arrest in the (A) MCF-7 -and (B) MDA-MB-468 cells. (C and D) After exposure to 6 Gy irradiation, MCF-7 cells did not exhibit obvious G2/M arrest following treatment with Huaier. Changes in cell cycle progression may be due to cyclin D1 and CDK4 in the (E) MCF-7 and (F) MDA-MB-468 cells. * $\mathrm{p}<0.05$ and ${ }^{* *} \mathrm{p}<0.01$ indicate a significant difference compared with the control (Student's t-test). The experiments were performed in triplicate, and data are presented as mean \pm SD of three separate experiments.

genes mainly related to cell cycle, cell division, cell cycle phases and DNA repair, with its -Lg (p-value) listed on the left and DEG count to the right of the figure, respectively. Table I shows the top $10 \mathrm{GO}$ categories affected by Huaier treatment in comparison to the control cells.
Huaier sensitizes breast cancer cells to irradiation. The cell cycle and DNA repair are closely related to irradiation, thus in order to ascertain whether Huaier has a radiosensitization effect on breast cancer cells, a colony formation assay was carried out. Fig. 1B shows the effect of Huaier on MCF-7 
A
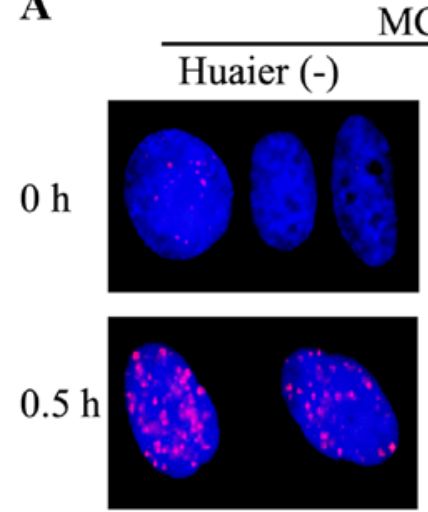

$4 \mathrm{~h}$

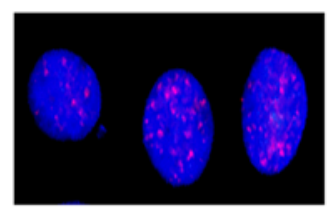

$8 \mathrm{~h}$

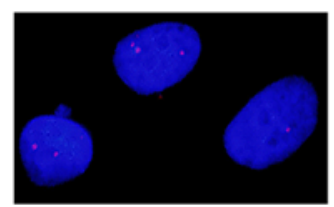

$12 \mathrm{~h}$

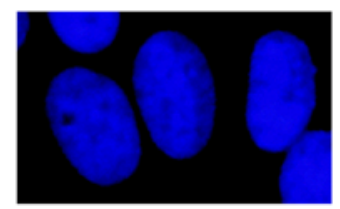

MCF-7
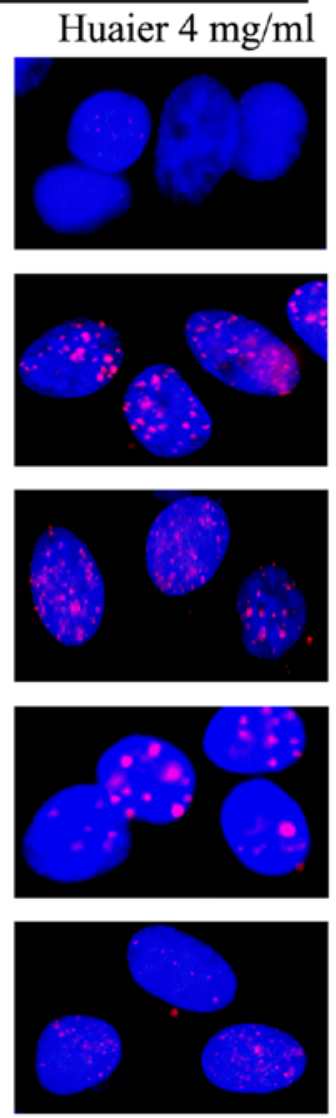

B

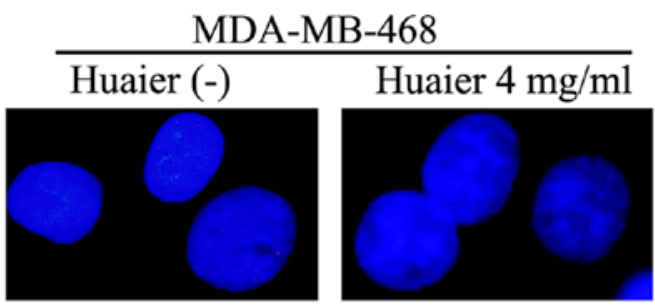

$0.5 \mathrm{~h}$
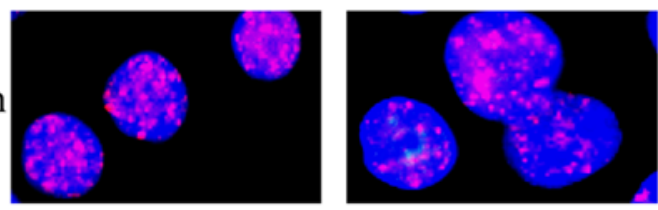

$4 \mathrm{~h}$
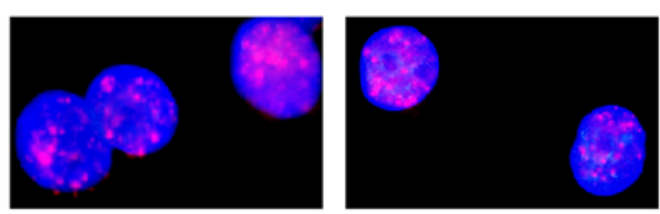

$8 \mathrm{~h}$
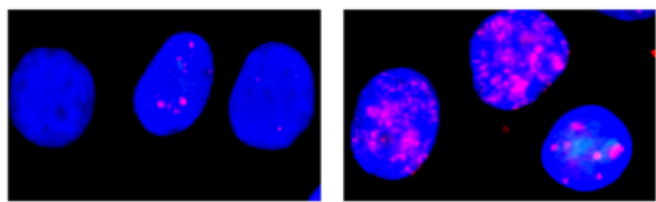

$12 \mathrm{~h}$
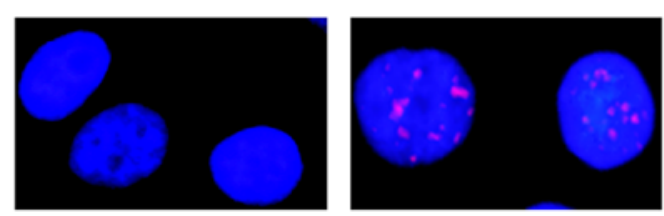

Figure 3. Detection of $\gamma$-H2AX foci using immunofluorescence staining. In cells without Huaier treatment, most $\gamma$-H2AX foci appeared at 0.5 h, decreased at $4 \mathrm{~h}$, and almost cleared at $8 \mathrm{~h}$, while in cells pretreated with Huaier, $\gamma-\mathrm{H} 2 \mathrm{AX}$ foci were not completely cleared even at $12 \mathrm{~h}$. Results are shown for (A) MCF-7 and (B) MDA-MB-231 cell lines. Three separate experiments were repeated with similar results.

and MDA-MB-468 breast cancer cells relative to radiation. The survival fraction at $2 \mathrm{~Gy}$ (SF2) was used to evaluate the radiosensitivity. In the MCF-7 cells, SF2 was $28.55 \pm 0.03 \%$ for cells pretreated with Huaier and $54.54 \pm 0.12 \%$ for the control, with a significant reduction of $\sim 47.65 \%(\mathrm{p}=0.018)$. Next, the linear quadratic formula was used to analyze the $\alpha$ and $\beta$ components. The $\alpha$ and $\beta$ values were $0.529 \pm 0.095 /$ Gy and $0.033 \pm 0.037 / \mathrm{Gy}^{2}$ for cells pretreated with Huaier, $-0.094 \pm 0.349 / \mathrm{Gy}$ and $0.034 \pm 0.054 / \mathrm{Gy}^{2}$ for the control cells, suggesting two significantly different curves using linear regression analysis $(\mathrm{p}<0.01)$. For the MDA-MB-468 cells, SF2 was $30.19 \pm 0.08 \%$ for cells pretreated with Huaier, and $50.96 \pm 0.06 \%$ for the control cells respectively, with a reduction of $40.76 \%(\mathrm{p}=0.026)$. The $\alpha$ and $\beta$ values were calculated at $0.703 \pm 0.170 / \mathrm{Gy}$ and $-0.019 \pm 0.052 / \mathrm{Gy}^{2}$ for cells pretreated with Huaier, and $0.297 \pm 0.034 / \mathrm{Gy}$ and $0.007 \pm 0.010 / \mathrm{Gy}^{2}$ for the control cells, again, demonstrating significant differences with and without Huaier $(\mathrm{p}<0.01)$, suggesting the radiosensitizing potential of Huaier.

Huaier treatment causes G0/G1 arrest. Flow cytometry was used to analyze cell cycle progression. As shown in Fig. 2A and B, when cells were treated with Huaier at $4 \mathrm{mg} / \mathrm{ml}$ for $24 \mathrm{~h}$, a significant increase in the percentage of cells in the G0/G1 phase was observed (from $32.33 \pm 1.64$ to $49.49 \pm 0.86 \%$ in MCF-7 cells, $\mathrm{p}<0.01$; from $46.44 \pm 1.89$ to $66.04 \pm 2.35 \%$ in
MDA-MB-468 cells, $\mathrm{p}<0.01$ ), accompanied by an obvious decrease in the percentage of cells in the $S$ phase (from $65.07 \pm 1.89$ to $45.04 \pm 0.85 \%$ in MCF-7 cells with $\mathrm{p}<0.01$, and from $42.79 \pm 2.01$ to $26.02 \pm 1.05 \%$ in MDA-MB-468 cells with $\mathrm{p}<0.01)$. Within $24 \mathrm{~h}$ after irradiation, the MCF-7 radiated cells (6 Gy) were found to have a block at the G2/M phase, whereas in cells pre-treated with Huaier this radiation-induced G2/M phase block was not obvious (Fig. 2C and D). To determine the mechanism of G0/G1 arrest, we detected the protein levels of cell cycle-regulating proteins by western blotting (as shown) and were able to demonstrate that two important cell cycle-regulating proteins, cyclin D1 and CDK4, were obviously decreased in both cell lines following treatment with Huaier, which may explain the G0/G1 cell cycle arrest for both cell lines (Fig. 2E and F).

Huaier pre-treatment prolongs the persistence of DNA double-strand breaks (DSBs). $\gamma-\mathrm{H} 2 \mathrm{AX}$ foci were detected using immunofluorescence staining to evaluate conditions of DNA double-strand breaks (DSBs) (27) at 0, 0.5, 4, 8 and $12 \mathrm{~h}$ after $1 \mathrm{~Gy}$ irradiation in both the MCF-7 and MDA-MB-468 cells. Both cell lines displayed similar phenomenon as shown in Fig. 3. In cells without Huaier treatment, $\gamma-\mathrm{H} 2 \mathrm{AX}$ foci appeared most prominently at $0.5 \mathrm{~h}$, decreased at $4 \mathrm{~h}$, and almost cleared at $8 \mathrm{~h}$, while in cells pretreated with Huaier, $\gamma$-H2AX foci were not completely cleared even at $12 \mathrm{~h}$. Thus, 
A

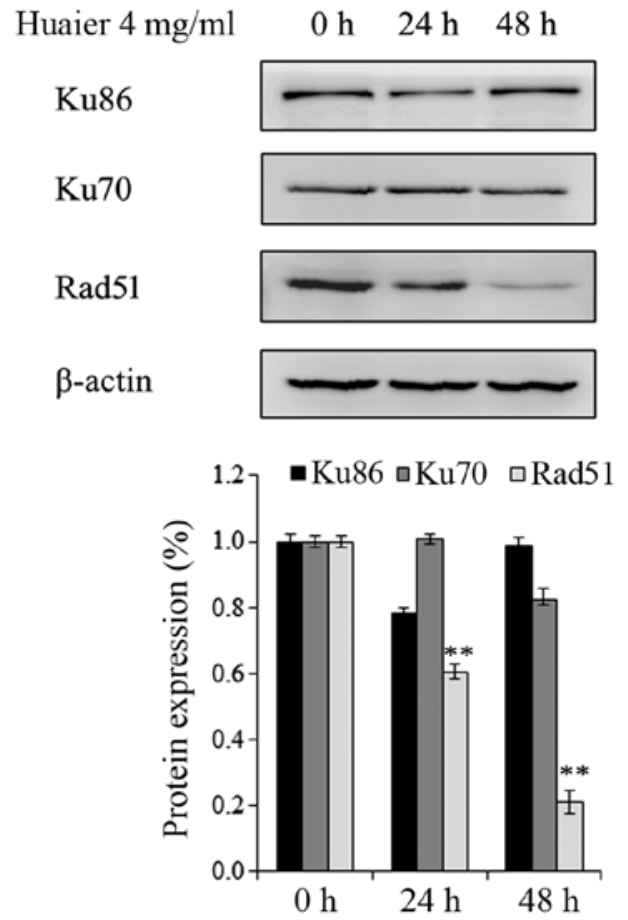

B

Huaier $4 \mathrm{mg} / \mathrm{ml}$

Ku86
Ku70
Rad51
$\beta$-actin
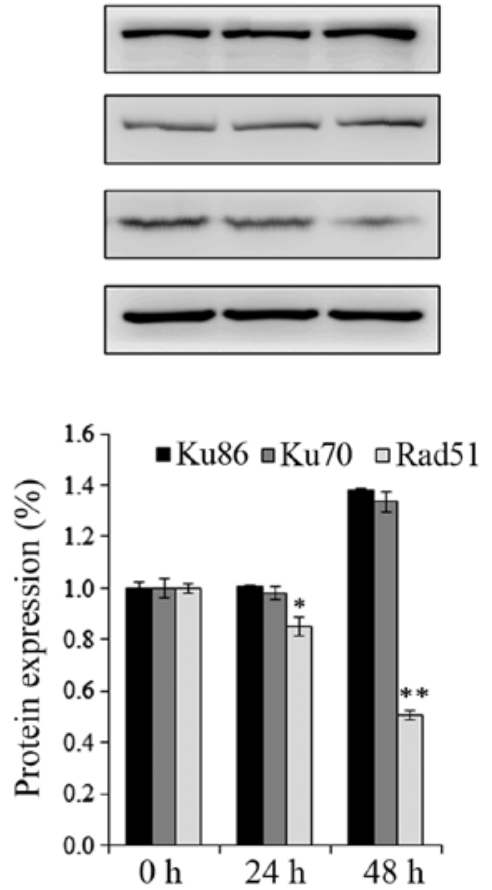

$\begin{array}{lllllllll}\mathrm{IR} 6 \mathrm{~Gy} & + & + & + & + & + & + & + & + \\ \text { Huaier } 4 \mathrm{mg} / \mathrm{ml} & - & - & - & - & + & + & + & +\end{array}$ $\begin{array}{llllllll}0 \mathrm{~h} & 2 \mathrm{~h} & 6 \mathrm{~h} & 24 \mathrm{~h} & 0 \mathrm{~h} & 2 \mathrm{~h} & 6 \mathrm{~h} & 24 \mathrm{~h}\end{array}$

Ku86

$\mathrm{Ku} 70$

$\operatorname{Rad} 51$

$\beta$-actin
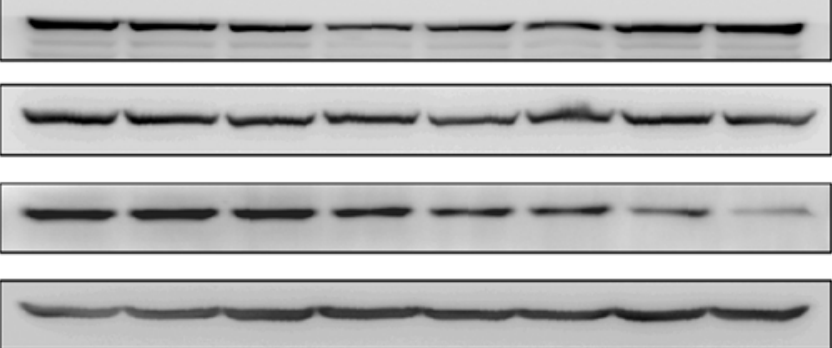

- Ku86 aKu70 aRad51

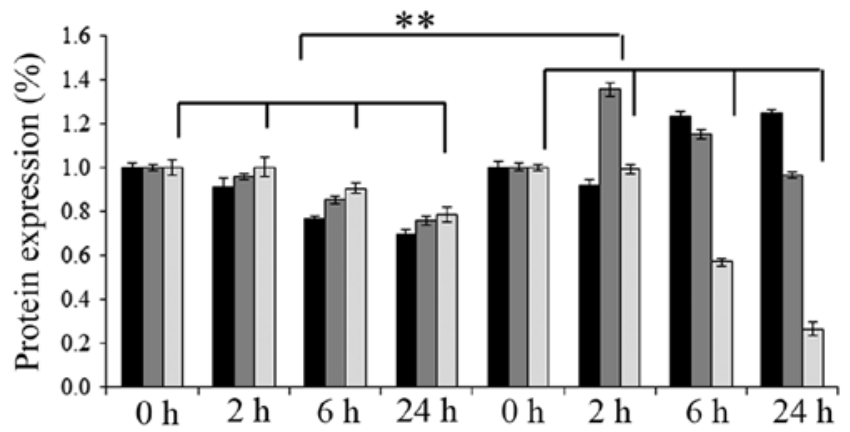

IR 6 Gy

Huaier $4 \mathrm{mg} / \mathrm{ml}$

$\begin{array}{llllllll}+ & + & + & + & + & + & + & + \\ - & - & - & - & + & + & + & +\end{array}$

$\begin{array}{llllllll}0 \mathrm{~h} & 2 \mathrm{~h} & 6 \mathrm{~h} & 24 \mathrm{~h} & 0 \mathrm{~h} & 2 \mathrm{~h} & 6 \mathrm{~h} & 24 \mathrm{~h}\end{array}$

Ku86

$\mathrm{Ku} 70$

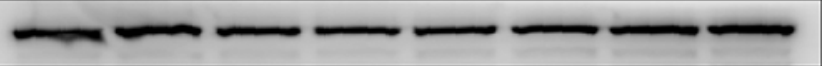

$\operatorname{Rad} 51$

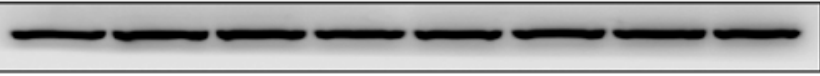

$\beta$-actin

- Ku86 घKu70 $\square \operatorname{Rad} 51$

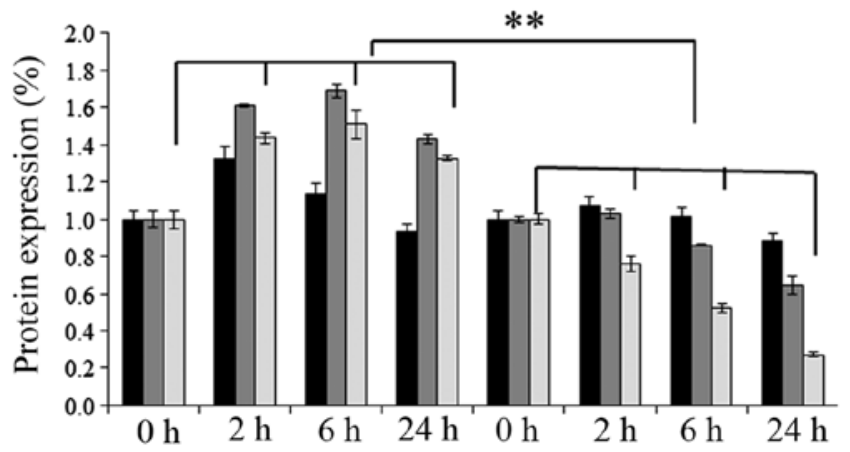

Figure 4. Huaier interferes with DNA repair through the homologous recombination (HR) pathway. For both (A) MCF-7 and (B) MDA-MB-468 cells, pretreatment with $4 \mathrm{mg} / \mathrm{ml}$ Huaier led to an obvious decrease in RAD51 but not Ku70 and Ku86. Following treatment with 6 Gy irradiation, the RAD51 level decreased time-dependently $(0,2,6$ and $24 \mathrm{~h})$ in cells pre-treated with Huaier compared to cells of the control. Three separate experiments were repeated with similar results. ${ }^{*} p<0.05$ and ${ }^{* * *} \mathrm{p}<0.01$ indicate a significant difference.

pre-treatment with Huaier prior to radiation appears to be associated with a longer interval of DSBs, which may contribute to its radiosensitization effect.
Huaier interferes with DNA repair through the homologous recombination (HR) pathway. Ku70 and Ku86 are markers of non-homologous end joining (NHEJ), while RAD51 is related 
to homologous recombination (HR). Fig. 4 shows the protein levels of $\mathrm{Ku} 70, \mathrm{Ku} 86$ and RAD51. In the MCF-7 cells, pretreatment of $4 \mathrm{mg} / \mathrm{ml}$ Huaier led to a decrease in RAD51 but not $\mathrm{Ku} 70$ and $\mathrm{Ku} 86$. In cells pre-treated with Huaier compared to the control cells, treatment with 6 Gy irradiation resulted in decreased RAD51 levels in a time-dependent fashion $(0,2,6$ and $24 \mathrm{~h}$ ). However, protein levels of $\mathrm{Ku} 70$ and $\mathrm{Ku} 86$ were not changed in either group (Fig. 4A). These results were similarly found in the MDA-MB-468 cells (Fig. 4B).

\section{Discussion}

Radiotherapy is an important and effective treatment strategy for breast cancer although it is sometimes limited by radioresistance and radiotoxicity. Thus, the identification of a radiosensitizer with a high benefit to risk ratio is needed. Recently, a wide variety of TCMs have been gaining popularity, and Huaier has been investigated by our group due to its seemingly low toxicity and antitumor activity (23,28-30).

The biologic effects of Huaier are varied (23), and its use has widely increased as a complementary treatment for cancers in recent years. In order to understand its mechanism of action specifically in breast cancer, a microarray assay of Huaier-treated MCF-7 breast cancer cells was assessed, which indicated that among the categories of cell cycle regulation, its effects are mainly related to cell cycle, cell division and DNA repair, thus making it a reasonable agent to investigate as a radiosensitizer. A colony formation assay was utilized to validate the hypothesis using MCF-7 and MDA-MB-468 breast cancer cells.

Our findings demonstrated that the percentage of cells in the $\mathrm{S}$ phase was significantly decreased in the Huaier-treated cells compared with the control, which may, in part, explain the radiosensitization phenomenon of Huaier. Moreover, irradiated cells pretreated with Huaier exhibited no obvious G2/M arrest, whereas irradiated cells had a significantly increased signal of $\mathrm{G} 2 / \mathrm{M}$ arrest, suggesting that Huaier combined with radiation can alter the cell cycle distribution and significantly alleviate $\mathrm{G} 2 / \mathrm{M}$ arrest, increasing sensitization to radiotherapy. These findings are consistent with other previously published studies on $\mathrm{G} 2 / \mathrm{M}$ arrest and irradiation sensitivity, which have demonstrated the association between $\mathrm{G} 2 / \mathrm{M}$ arrest and sensitization to irradiation $(31,32)$.

Cell cycle arrest is often related to cell cycle-regulating proteins. Cyclin D1 is an important regulator in cell cycle progression in $\mathrm{G} 1$ to $\mathrm{S}$ transition. By binding to CDK4, it phosphorylates $\mathrm{Rb}$ to release $\mathrm{E} 2 \mathrm{~F}$, which is required for transition from the G1 to $\mathrm{S}$ phase (33). In the present study, we found that the levels of cyclin D1 and CDK4 were significantly decreased in both cell lines following treatment with Huaier, which may explain the mechanism of G0/G1 arrest, particularly in the MDA-MB-468 cells. It is likely that Huaier regulates several cell cycle-related proteins, ultimately resulting in induced G0/G1 arrest.

It is well-known that the main mechanism of action of radiation for cell death is related to DNA damage (i.e. doublestrand DNA breaks), thus, cell mortality is proportional to the unrepaired DNA damage (34). Cells resistant to radiation develop various DNA repair pathways to protect the damaged DNA. These protective mechanisms are strong, and include
DNA repair pathways such as nucleotide excision repair (NER), mismatch repair (MMR), base excision repair (BER), non-homologous end joining (NHEJ) and homologous recombination (HR). In mammalian cells, HR and NHEJ are the main DNA repair pathways. In the present study, the western blot assay demonstrated that Huaier treatment decreased the protein level of RAD51 which is an important player in HR, but not Ku70 and Ku86 which are members of NHEJ. Yet, when irradiated with 6 Gy X-ray, the protein level of RAD51 was decreased in a time-dependent manner. This phenomenon indicates that Huaier treatment may inhibit the reparatory pathways that are elicited with irradiation. Moreover, since $\gamma$-H2AX foci are a biomarker of DNA double-strand breaks (35), as shown in the immunofluorescence assays, the DNA damage in Huaier-treated cells persisted for a longer period of time compared with that in the untreated cells. Various recent studies support the contention that compared with normal tissues, tumor cells have defects in DNA repair pathways in familial breast cancer and other cancers $(36,37)$. Thus, the ability to diminish one (or more) of the pathways of DNA repair may result in increased cell kill, and may be a potential target for increasing radiosensitization.

In conclusion, our results showed that Huaier has the ability to alter cell cycle progression by regulating protein levels of cell cycle-regulating proteins, and disrupting DNA repair through the HR pathway. These results suggest that Huaier should be investigated further as a potential radiosensitizer for breast cancer. While clinical correlation studies are needed to assess the toxicity and efficacy of Huaier treatment, our current investigation provides the laboratory basis to suggest that Huaier is promising for further clinical investigation in breast cancer patients.

\section{Acknowledgements}

The present study was supported by the National Natural Science Foundation of China (nos. 81272903 and 81172529), the Shandong Science and Technology Development Plan (no. 2013GRC31801), and the Special Support Plan for National High Level Talents ('Ten Thousand Talents Program') to Q.Y.

\section{References}

1. Torre LA, Bray F, Siegel RL, Ferlay J, Lortet-Tieulent J and Jemal A: Global cancer statistics, 2012. CA Cancer J Clin 65: 87-108, 2015.

2. Brown LC, Mutter RW and Halyard MY: Benefits, risks, and safety of external beam radiation therapy for breast cancer. Int $\mathrm{J}$ Womens Health 7: 449-458, 2015.

3. Gerweck LE, Vijayappa S, Kurimasa A, Ogawa K and Chen DJ: Tumor cell radiosensitivity is a major determinant of tumor response to radiation. Cancer Res 66: 8352-8355, 2006.

4. Uma Devi P: Normal tissue protection in cancer therapy progress and prospects. Acta Oncol 37: 247-252, 1998.

5. Thomson D, Yang H, Baines H, Miles E, Bolton S, West C and Slevin N: NIMRAD - a phase III trial to investigate the use of nimorazole hypoxia modification with intensity-modulated radiotherapy in head and neck cancer. Clin Oncol 26: 344-347, 2014.

6. Ang KK: More lessons learned from the suffocation of hypoxia. J Clin Oncol 28: 2941-2943, 2010.

7. Cragg GM and Newman DJ: Plants as a source of anti-cancer agents. J Ethnopharmacol 100: 72-79, 2005.

8. Chen P, Li J, Jiang HG, Lan T and Chen YC: Curcumin reverses cisplatin resistance in cisplatin-resistant lung cancer cells by inhibiting FA/BRCA pathway. Tumour Biol 36: 3591-3599, 2015. 
9. Shi XP, Miao S, Wu Y, Zhang W, Zhang XF, Ma HZ, Xin HL, Feng J, Wen AD and Li Y: Resveratrol sensitizes tamoxifen in antiestrogen-resistant breast cancer cells with epithelial-mesenchymal transition features. Int J Mol Sci 14: 15655-15668, 2013.

10. Srivastava V, Negi AS, Kumar JK, Gupta MM and Khanuja SP Plant-based anticancer molecules: A chemical and biological profile of some important leads. Bioorg Med Chem 13: 5892-5908, 2005.

11. Li LYS, Wang Y and Tang Z: Progress on experimental research and clinical application of Trametes robiniophila. China Cancer 16: 110-113, 2006.

12. Zheng J, Li C, Wu X, Liu M, Sun X, Yang Y, Hao M, Sheng S, Sun Y, Zhang H, et al: Huaier polysaccharides suppress hepatocarcinoma MHCC97-H cell metastasis via inactivation of EMT and AEG-1 pathway. Int J Biol Macromol 64: 106-110, 2014.

13. Li C, Wu X, Zhang H, Yang G, Hao M, Sheng S, Sun Y, Long J, $\mathrm{Hu}$ C, Sun X, et al: A Huaier polysaccharide reduced metastasis of human hepatocellular carcinoma SMMC-7721 cells via modulating AUF-1 signaling pathway. Tumour Biol 36: 6285-6293, 2015 .

14. Zhang T, Wang K, Zhang J, Wang X, Chen Z, Ni C, Qiu F and Huang J: Huaier aqueous extract inhibits colorectal cancer stem cell growth partially via downregulation of the $\mathrm{Wnt} / \beta$-catenin pathway. Oncol Lett 5: 1171-1176, 2013.

15. Wang X, Zhang N, Huo Q and Yang Q: Anti-angiogenic and antitumor activities of Huaier aqueous extract. Oncol Rep 28 $1167-1175,2012$

16. Zhang N, Kong X, Yan S, Yuan C and Yang Q: Huaier aqueous extract inhibits proliferation of breast cancer cells by inducing apoptosis. Cancer Sci 101: 2375-2383, 2010.

17. Wu T, Chen W, Liu S, Lu H, Wang H, Kong D, Huang X, Kong Q, Ning Y and Lu Z: Huaier suppresses proliferation and induces apoptosis in human pulmonary cancer cells via upregulation of miR-26b-5p. FEBS Lett 588: 2107-2114, 2014.

18. Zhang F, Zhang Z and Liu Z: Effects of Huaier aqueous extract on proliferation and apoptosis in the melanoma cell line A875. Acta Histochem 115: 705-711, 2013.

19. Cui Y, Meng H, Liu W, Wang H and Liu Q: Huaier aqueous extract induces apoptosis of human fibrosarcoma HT1080 cells through the mitochondrial pathway. Oncol Lett 9: 1590-1596, 2015.

20. Li C, Wu X, Zhang H, Yang G, Hao M, Sheng S, Sun Y, Long J, $\mathrm{Hu}$ C, Sun X, et al: A Huaier polysaccharide inhibits hepatocellular carcinoma growth and metastasis. Tumour Biol 36: $1739-1745,2015$.

21. Sun Y, Sun T, Wang F, Zhang J, Li C, Chen X, Li Q and Sun S: A polysaccharide from the fungi of Huaier exhibits anti-tumor potential and immunomodulatory effects. Carbohydr Polym 92: $577-582,2013$
22. Yu Zhe WT and Yang Z: The reversal effects of Trametes Robiniophila Murr. on multidrug resistance in resistant human hepatocellular carcinoma cell line BEL-7402/5-Fu. J Clin Oncol 19: 443-447, 2013.

23. Kong X, Ding $X$ and Yang Q: Identification of multi-target effects of Huaier aqueous extract via microarray profiling in triple-negative breast cancer cells. Int J Oncol 46: 2047-2056, 2015.

24. Gene Ontology Consortium: The Gene Ontology (GO) project in 2006. Nucleic Acids Res 34: D322-D326, 2006.

25. Ashburner M, Ball CA, Blake JA, Botstein D, Butler $\mathrm{H}$, Cherry JM, Davis AP, Dolinski K, Dwight SS, Eppig JT, et al; The Gene Ontology Consortium: Gene ontology: Tool for the unification of biology. Nat Genet 25: 25-29, 2000.

26. Franken NA, Rodermond HM, Stap J, Haveman J and van Bree C Clonogenic assay of cells in vitro. Nat Protoc 1: 2315-2319, 2006.

27. Gerić M, Gajski G and Garaj-Vrhovac V: $\gamma$-H2AX as a biomarker for DNA double-strand breaks in ecotoxicology. Ecotoxicol Environ Saf 105: 13-21, 2014.

28. Cohen I, Tagliaferri $M$ and Tripathy D: Traditional Chinese medicine in the treatment of breast cancer. Semin Oncol 29: 563-574, 2002.

29. Wong KY, Tan EY, Chen JJ, Teo C and Chan PM: The use of traditional Chinese medicine among breast cancer patients: Implications for the clinician. Ann Acad Med Singapore 43: 74-78, 2014.

30. Wang X, Zhang N, Huo Q, Sun M, Lv S and Yang Q: Huaier aqueous extract suppresses human breast cancer cell proliferation through inhibition of estrogen receptor $\alpha$ signaling. Int $\mathrm{J}$ Oncol 43: 321-328, 2013.

31. Busse PM, Bose SK, Jones RW and Tolmach LJ: The action of caffeine on X-irradiated HeLa cells. III. Enhancement of X-rayinduced killing during G2 arrest. Radiat Res 76: 292-307, 1978.

32. Wang J,Liu Q and Yang Q: Radiosensitization effects of berberine on human breast cancer cells. Int J Mol Med 30: 1166-1172, 2012.

33. Giacinti $\mathrm{C}$ and Giordano A: RB and cell cycle progression. Oncogene 25: 5220-5227, 2006.

34. Núñez MI, McMillan TJ, Valenzuela MT, Ruiz de Almodóvar JM and Pedraza V: Relationship between DNA damage, rejoining and cell killing by radiation in mammalian cells. Radiother Oncol 39: 155-165, 1996.

35. Kuo LJ and Yang LX: Gamma-H2AX - a novel biomarker for DNA double-strand breaks. In Vivo 22: 305-309, 2008.

36. Shibata D: When does MMR loss occur during HNPCC progression? Cancer Biomark 2: 29-35, 2006.

37. Powell SN and Kachnic LA: Therapeutic exploitation of tumor cell defects in homologous recombination. Anticancer Agents Med Chem 8: 448-460, 2008 